\title{
MEMÓRIAS DA EDUCAÇÃO: A ALFABETIZAÇÃ̃ DE JOVENS E ADULTOS EM 40 HORAS (ANGICOS/RN, 1963)
}

\author{
Maria Elizete Guimarães Carvalho ${ }^{1}$ \\ Universidade Federal da Paraíba - UFPB \\ mecarvalho23@yahoo.com.br \\ Maria das Graças da Cruz Barbosa ${ }^{2}$ \\ Universidade Federal da Paraíba - UFPB \\ gracacruz25@hotmail.com
}

\begin{abstract}
RESUMO
O propósito desse estudo é refletir sobre as memórias do projeto de alfabetização denominado 40 Horas de Angicos, experiência de educação popular desenvolvida no início dos anos 1960, na cidade de Angicos/RN. As memórias dessa experiência educacional caracterizam-se pelos aspectos de transformação e de conservação, encontrando-se em processo de desaparecimento, tendo em vista o esquecimento, a amnésia e o retraimento que caracterizam o ato de lembrar nos indivíduos e nas sociedades. Considerando essa afirmação, o artigo também discute as relações entre história e memória, a importância de um trabalho conjunto que contemple e recolha vivências, vestígios, reminiscências, eventos educacionais, enriquecendo o campo epistemológico da História da Educação. As 40 Horas de Angicos alfabetizou cerca de 300 adultos em 40 horas, utilizando-se de práticas educacionais orientadas por Paulo Freire, estando presente nas lembranças, nos silêncios e nos esquecimentos dos participantes, que denunciaram a extinção dos vestígios, como a destruição dos espaços que foram círculos de cultura, o desaparecimento da memória e da história. As reflexões fundamentaram-se nos estudos de Bergson, Halbwachs, Hobsbawm sobre a memória.
\end{abstract}

Palavras-chave: Memória, História, Método Paulo Freire, Alfabetização de Jovens e Adultos.

\section{EDUCATION MEMORIES: THE YOUTHS AND ADULTS ALPHABETIZATION IN 40 HORS (ANGICOS/RN, 1963)}

\begin{abstract}
:
The study object is reflect about the memories of the alphabetization project named 40 Horas de Angicos, popular educational experience developed in the beginning of 1960, in Angicos/RN. The memories of this educational experience characterize themselves by the transformation and conservation aspects, being in adisappear process, considering the forgetfulness, the amnesia and the retraction that characterize de remember act in the people and in the societies. Considering this affirmation, the article also discusses the relationship between history and memory, the importance of a joint work that contemplates and furls lives, vestiges, reminiscences, educational events, enriching the epistemological camp of Educational History. The 40 Horas de Angicos alphabetized about 300 adults in 40 hours, using educational practices guided by Paulo Freire, being in the regards, in the silence and in the forgetfulness of the participators, those appointed the vestiges extinction, as the destruction of the spaces that were culture circles, the history and memory disappear. The reflections based upon the Bergson, Halbwachs and Hobsbawn studies about memory.
\end{abstract}

Key-works: Memory, History, Paulo Freire's Method, Youths and Adults Alphabetization. 


\section{Introdução}

Refletir sobre as memórias da educação implica na apropriação de reminiscências e de trajetórias pessoais e documentais, na compreensão de muitas formas de representação da vida e da realidade, que possibilitam leituras e interpretações do fato educacional, em um trabalho de captação e reconstrução de sentidos e de significações.

No trabalho de mobilização da memória, o historiador recolhe os artefatos do passado, como aquele que "escova a história a contrapelo" (BENJAMIN, 1994, p. 225), ou como aquele que mergulha sob as ondas (BURKE, 1991), trazendo para o contexto da pesquisa educacional, discursos, registros, cartas, biografias, diários, imagens, testemunhos, enfim, tudo que contenha "a possibilidade de vislumbrar a ação humana" (KARNAL; TATSCH, 2009, p. 15) no campo educativo e de compreendê-la. São reminiscências, centelhas de um passado, de um acontecimento, que se entregam para apropriação/interpretação.

Nesse sentido, não se conhece o passado como ele de fato foi. As memórias, os documentos são tratados pelo olhar, pela abordagem do historiador, para o que contribuem história de vida, formação, crenças e os pressupostos da investigação científica, valendo lembrar que tais reminiscências, incluindo os testemunhos orais, já passaram pela seleção da memória, pelas opções do colecionador ou de quem as preservou. "[...] o passado nunca permanece uno e idêntico a si, mas é constantemente selecionado, filtrado e reestruturado por questões e necessidades do presente, tanto no nível individual como no social" (JEDLOWSKI, 2005, p. 87). Nesse contexto, não existe abismo, lacuna entre história e memória, mesmo que a memória trate o objeto de estudo em uma perspectiva interior e a história o investigue de uma perspectiva externa, ou como entendeu Agnes Heller: a história "trata do que acontece visto de fora, e as memórias tratam do que acontece visto de dentro" (HELLER, apud HOBSBAWM, 2002, p. 12).

$\mathrm{Na}$ esteira dessa reflexão, não se tem a pretensão de conhecer o acontecimento educacional 40 Horas de Angicos como ele de fato aconteceu, mas pretende-se compreendê-lo como é percebido no atual momento histórico, quase 50 anos depois, por aqueles que o vivenciaram, verificando em que fase da memória individual e coletiva ele se encontra, se em extinção ou em transbordamento. A apropriação das reminiscências toma os testemunhos orais como matéria da história e da memória.

É nessa configuração que o movimento de educação popular ocorrido no início dos anos 1960, está sendo tratado: como história e como memória. Mas porque investigar as memórias desse movimento? Primeiro porque a primeira versão foi escrita faz algum tempo, cerca de 15 anos, e nesse espaço temporal, tanto a memória individual como a coletiva sofreram transformações, pela própria natureza da memória, que é preservação e transformação. Segundo, porque a história dos participantes ainda está por escrever. E terceiro, porque é necessário reconstituir a memória para livrá-la do esquecimento.

Somando-se a estas razões, está um conjunto de memórias acadêmicas, lembranças acumuladas durante a tese de doutoramento, em que o foco da pesquisa era a Campanha de Pé no Chão Também se Aprende a Ler. Inserida em um cenário de lutas e movimentos sociais pela educação, tanto o aporte teórico trabalhado como o metodológico (falando em educação popular, história oral, colaboradores/entrevistados) abordavam o tema em debate, as 40 Horas de Angicos.

Assim, no processo de investigação das memórias de pessoas que vivenciaram ativamente esse momento histórico, o início dos anos 1960, como estudantes universitários, organizadores, monitores e alunos, registraram-se depoimentos como os de Vasconcelos (2000), professor aposentado da Universidade Federal do Rio Grande do Norte, que na época era lider estudantil e participava ativamente das mobilizações em Natal. Em conversa 
informal, o Pofessor observou que a origem das 40 Horas de Angicos podia ser buscada, também, na Campanha de Pé no Chão, pois foi o seu sucesso na educação municipal de Natal, que orientou o Governador do Estado, Sr. Aluízio Alves, a procurar o Professor Paulo Freire, em Recife, e convidá-lo para orientar e organizar esse projeto educacional, que teria como local de testagem a cidade de Angicos. Tratava-se de uma proposta avançada de educação de base que previa a alfabetização de 100 mil adultos, por um período de três anos, durante a gestão do Governador Aluízio Alves (CARVALHO, 2000).

Nesse sentido, vale explicar, que o passado não é apenas o momento anterior ao presente, mas sua fonte. O que fomos e o que somos estão desde sempre imbricados, conectados. O conhecimento do presente - fatos, acontecimentos, processos, teorias, estruturas - permitem compreender e avaliar acontecimentos passados. Ou tomando de empréstimo a compreensão de Bergson (1990) sobre a temática, ao referir que é só pelo passado que se pode conhecer o presente e o futuro. E ainda, a afirmação de Soares (2001, p. 22), ao explicar o ato acadêmico que está praticando a partir da analogia Marxiana:

[...]'A anatomia do homem é a chave da anatomia do macaco'. E explica: 'Nas espécies animais inferiores, só se podem compreender os signos denunciadores de uma forma superior quando essa forma superior é já conhecida.' A analogia serve a Marx para demonstrar como a compreensão da sociedade burguesa, organização social mais complexa e desenvolvida, permite compreender as estruturas sociais que a antecedem. Tomo emprestado a analogia para dizer que a compreensão do ato acadêmico que agora pratico [...] é chave para a compreensão do passado, que só pode ser avaliado a partir de seus efeitos.

Em pressupostos como esses encontra fundamento a preocupação do historiador da educação, que compreende ser imprescindível a construção de uma ponte entre presente e passado para interpretação e resolução das questões atuais (e vice-versa) que marcam o trabalho educativo, para projeção do futuro, com mais segurança e possibilidade de acertos. Cabe então afirmar a necessidade de investigação do passado, de sua reelaboração, contribuindo para o intercâmbio de experiências entre presente e pretérito, fato que se registra como fundamental na sociedade contemporânea, por presenciar-se o crescimento de gerações em uma espécie de presente contínuo.

Nesse sentido, é preciso lutar contra o esquecimento, recriando fatos e acontecimentos, enfrentando o tempo que destrói a matéria histórica, lutando contra o declínio da história e da memória. O alerta de Hobsbawm (1995, p. 13) tem esse significado.

A destruição do passado - ou melhor, dos mecanismos sociais que vinculam nossa experiência pessoal à de gerações passadas - é um dos fenômenos mais característicos e lúgubres do final do século XX. Quase todos os jovens de hoje crescem numa espécie de presente contínuo, sem qualquer relação orgânica com o passado público da época em que vivem.

A reflexão sobre esta assertiva e experiências do cotidiano docente têm orientado para investigações na área de História da Educação, tomando a memória como objeto de estudo para a reconstituição histórica ${ }^{3}$.

É nesse sentido o propósito do presente trabalho: refletir sobre as memórias do projeto educacional 40 Horas de Angicos, em um processo de reconstituição mnemônica, que considera esse espaço investigativo um campo privilegiado, tanto no plano histórico como no plano pedagógico, revelando práticas de naturezas diversas - humanas, culturais e 
profissionais - do fazer educativo, e ao mesmo tempo, sentimentos, dores lembranças, desejos, anseios modelados no contexto temporal.

\section{Articulação entre história e memória}

Quando se opta pela memória como testemunha, tem-se a consciência de que ela trabalha com a seleção dos eventos, não sendo capaz de restituir/reconstituir o passado por inteiro. Acredita-se no trabalho da historiografia que se abre para a memória, que aposta no vivido, em que os fatos da memória enriquecem os acontecimentos da história, o que nos permite afirmar que não há como separar os fatos de sua interpretação. A História não é mais importante que a Memória. A função do historiador pode ser comparada ao catador de trapos de Walter Benjamin. Não há que selecionar os cacos do passado, os mais valiosos dos aparentemente sem valor. "[...] a felicidade do catador-colecionador advém de sua capacidade de reordenação salvadora desses materiais abandonados pela humanidade carregada pelo 'progresso' no seu caminhar cego" (SELIGMANN-SILVA, 2003, p. 77). Nessa compreensão, todos os vestígios do passado devem ser recolhidos, orientando para um trabalho conjunto entre história e memória, o que enriquecerá o campo epistemológico da História da Educação.

Nessa configuração de reconstituição da memória e reconstrução histórica, saberes e práticas se articulam e se completam, constituindo-se um conjunto qualitativo de conhecimentos, resultante de acontecimentos que já se concretizaram como história, ou de elaborações guardadas/transformadas pela memória. Porque não se sabe ainda o tempo de vida das lembranças, sabe-se, no entanto, que elas passam por processos de transformação, recriação e seleção, implicando que as memórias são representações/interpretações dos acontecimentos. A explicação de Hobsbawm contribui para a compreensão: "[...] Não sei quando se inicia a vida da memória, mas a maior parte dela não recua à idade de dois anos" (HOBSBAWM, 2002, p. 17).

No contexto do vivido e do representado, o historiador da Educação não deve fazer escolhas. Seu ponto de partida é a preocupação com o presente. Um presente que demanda explicações e interpretações, sentidos para os acontecimentos. Tem origem então a necessidade de revisitar o passado, de traçar seu mapa, para seguir seus caminhos, suas paisagens, cenários, compreender seus motivos e momentos, retraçando um roteiro investigativo. Tal passado, no plano da memória, é lembrança e esquecimento. São recordações de ações, sentimentos, imagens, conhecimentos selecionados a partir de interesses, anseios e desejos ancorados no tempo presente. É como ensina Hobsbawm (2002, p. 21):

O passado é um outro país, mas deixou sua marca nos que o habitaram. Marcou também os que eram demasiadamente jovens para havê-lo conhecido a não ser por ouvir dizer, ou mesmo numa civilização estruturada de maneira a-histórica, para tratá-lo como coisa banal, como no jogo trivial pursuit, que teve passageira fama no final do século XX.

A abordagem mnemônica configura-se como um trabalho que permite reavaliar toda a análise historiográfica anterior, considerando os acontecimentos históricos e os fatos da memória, incluindo o seu sentido hermenêutico, construindo de forma estruturada, acontecimentos da História da Educação, constituída de idéias, práticas e cultura escolar. Ora, são diversas as trilhas da memória, assim como são muitas as suas faces. 
A história trata dos acontecimentos vistos de fora, em uma visão externa do tempo, da realidade. O tempo histórico não é o tempo vivido. A história escrita, documentada, distinguese do acontecido; é uma representação.

É nesse sentido a afirmação de Montenegro (1996, p. 19):

Com a história, a dimensão do fato, do acontecido, do acontecimento opera sempre em sintonia com o que é estabelecido no momento em que o fato ocorreu. A forma como o acontecido operou ou atuou no imaginário ou no próprio comportamento social não se constitui em elemento fundante.

Desse modo, a história trabalha com o que se torna público ou vem à tona na sociedade, em determinado momento e lugar. É uma representação do real, que se refaz e se reformula a partir de novos questionamentos do historiador, ou através das descobertas de novos documentos ou fontes.

$\mathrm{Na}$ investigação em desenvolvimento, a história está sendo considerada a partir desses pressupostos, como representação do real, de acontecimentos passados/presentes que ocuparam/ocupam o maior espaço na memória da humanidade. Já a memória está sendo compreendida como experiência vivida, como conservação e transformação.

Ora, na história escrita existem muitas lacunas que precisam ser preenchidas para a (re)significação de uma antiga visão/concepção, o que pode ser feito pela reconstituição da memória coletiva/individual.

Considerando esse pressuposto, o que foi transformado e o que foi preservado na memória dos participantes das 40 Horas de Angicos?

\section{Trilhando a história e as memórias das 40 horas de Angicos}

Surgido no cenário das lutas e movimentos sociais por reformas de base do início dos anos 1960, o projeto de alfabetização 40 Horas de Angicos apresenta características peculiares que o diferenciam das campanhas e movimentos de educação popular originados na época, apesar do espírito ser o mesmo. Trata-se de um experimento localizado, dentro das previsões do Plano Estadual de Educação, tendo como núcleo experimental a cidade de Angicos. Foi estruturado "por iniciativa do governo estadual do Rio Grande do Norte, em convênio com a Superintendência para o desenvolvimento do Nordeste (SUDENE) e United States Agency for International Development (USAID)" (GERMANO; PAIVA, 2006, p. 12).

Nesse estudo, pretendeu-se promover um encontro entre história e memória, revisitando a história ${ }^{4}$ e reconstituindo as memórias dos participantes da experiência educacional com jovens e adultos, 40 Horas de Angicos. Também, foram examinadas algumas práticas educativas desenvolvidas e as possíveis contribuições para o trabalho educacional com a modalidade jovens e adultos atualmente, promovendo um diálogo entre experiências passadas e presentes, mediante o resgate de lembranças desse acontecimento histórico, viabilizando um encontro com as memórias individual e coletiva. Em face desses propósitos, investigaram-se as representações que os participantes têm dessa experiência educacional, as marcas deixadas em sua memória, as contribuições das práticas educacionais e sociais desenvolvidas para educação de jovens e adultos no presente, os cruzamentos entre História e Memória nas narrativas dos participantes.

No processo de pesquisa, foram criadas estratégias de investigação, proporcionando aos participantes representarem suas experiências e aquisições intelectuais, considerando o trabalho com fontes escritas e o processo metodológico de pesquisa da História Oral. 
Vale então conhecer melhor a pequena cidade do sertão norte-riograndense, onde ocorreu a experiência educacional, o que é feito com as Professoras Silva; Alcântara; Eleutério (2006, p. 7):

\author{
Angicos! \\ Sertão do Centro Norte do Estado \\ Distante $170 \mathrm{~km}$ da capital \\ Angicos do Pico do Cabugi \\ Do famoso banho de gangorra \\ Da cerâmica, dos chapéus de palha \\ Das esteiras e talhas de madeira. \\ Angicos da dança do camaleão \\ Do xiquexique, do mandacaru \\ Terra de cantadores e poetas \\ Da beleza das serras \\ Pátria de Aluízio Alves... político cristalizado no tempo. \\ Angicos! \\ Cenário ideal para realização da primeira experiência \\ Sistematizada de alfabetização de adultos.
}

O poema fala por si só. Angicos era o espaço ideal para a realização da experiência de alfabetização. A proposta educacional tinha como propósito diminuir o alto índice de analfabetismo no Estado, que nesse momento, atingia $70 \%$ da população adulta, ficando sob a responsabilidade do Serviço Cooperativo da Educação do Rio Grande do Norte (SECERN), tendo como orientação pedagógica o sistema de alfabetização de adultos elaborado por Paulo Freire, em Recife, que já estava apresentando resultados positivos, embora não tivesse sido utilizado em grande escala.

A escolha da equipe de coordenadores ficou sob a responsabilidade de Paulo Freire e era composta, em sua maioria, por estudantes universitários de Natal, treinados em Recife. Freire teve em sua formação, inicialmente, marcada influência 'isebiana' e pelo ideário nacional-desenvolvimentista. O nacionalismo e a educação foram tomados como formas de resistência cultural, salvadoras do atraso e subdesenvolvimento (GERMANO; PAIVA, 2006, p. 13).

Essa equipe de trabalho, além dos coordenadores, contava com monitores, também estudantes universitários de Natal, da récem-fundada Universidade Federal do Rio Grande do Norte, estudantes dos Cursos de Direito, de Serviço Social, de Engenharia, entre outros, filhos, em sua maioria de famílias tradicionais do Estado. Esses jovens, imbuídos das ideias que se veiculavam na época, foram para Angicos, nas férias do início do ano de 1963, para desenvolverem o projeto piloto de alfabetização de adultos em 40 horas.

Distante cerca de $170 \mathrm{~km}$ da capital do Estado, Angicos, terra natal do então Governador, situa-se na messoregião central, apresentando, na época, um percentual elevado de analfabetos. Ora, o colégio eleitoral não atingia nem 600 eleitores e só os alfabetizados podiam votar. Tendo em vista essa grave situação, e entre outras questões, a cidade foi escolhida para a testagem da experiência piloto do projeto.

Assessorado por Paulo Freire, o Professor Marcos Guerra, então estudante de Direito e líder estudantil, efetivou a capacitação da equipe pedagógica com a realização de Seminário de Formação de Professores, ocorrido na Faculdade de Direito. Durante o processo, os participantes eram orientados/assessorados por Paulo Freire, duas vezes por mês. 
Seguindo as orientações e metodologia do trabalho desenvolvido por Freire na capital pernambucana, Marcos Guerra e sua equipe instalaram-se em Angicos e deram início à experiência educacional que marcaria não só a população angicana, mas o Nordeste e o Brasil.

Assim, iniciaram a experiência pela investigação da realidade lingüística dos alfabetizandos para escolha do universo vocabular a ser trabalhado. Desse universo foram retiradas as palavras e temas geradores, originadores do debate, que seriam empregados no processo de alfabetização, sendo a escolha realizada de acordo com a relevância e significado social para o grupo envolvido. Assim explicou Guerra em entrevista ao jornal Tribuna do Norte (GUERRA apud MADRUGA, 2005, p. 01): "Nós, como monitores, fazíamos uma pesquisa investigando a vida das pessoas. Não adianta ensiná-los palavras da cartilha do Ministério de Educação, se não faziam parte do universo vocabular de cada um. Não haveria utilidade".

Conforme assinalam Germano; Paiva (2006, p. 13), as palavras que mais significavam àquela realidade, prestando-se a uma leitura de mundo do cotidiano angicano, foram as seguintes: "belota (corruptela de borla ou bolota), voto, povo, salina, feira, milho, goleiro, cozinha e tigela, todas escolhidas no levantamento do universo vocabular dos alunos".

A partir dessas palavras geradoras, todo material didático era preparado, como fichas de leitura, slides, entre outros. Silva; Alcântara; Eleutério (2006, p. 08) explicam o funcionamento das aulas:

\begin{abstract}
As aulas eram desenvolvidas através de situações-problema, estimulando a participação e o posicionamento crítico do educando, de modo que o adulto se educava mediante a discussão de suas experiências de vida com outros indivíduos que participavam das mesmas experiências, num processo em que o homem 'aprende a si mesmo e aos outros sob a mediação do mundo'. Assim se dava a leitura da palavra, passando pelo reconhecimento dos fonemas e das sílabas até a leitura de frases que traduzem as relações com o mundo.
\end{abstract}

Pelo visto, era uma metodologia diferente, inovadora ou alternativa para o desenvolvimento do trabalho pedagógico com jovens e adultos. As propostas de alfabetização contidas no sistema Paulo Freire não fazem da cartilha, instrumento principal do processo ensino-aprendizagem, mas dos "círculos de cultura", que em substituição às tradicionais salas de aula, constituiam-se os espaços onde se desenvolviam o debate que davam origem ao processo de alfabetização e conscientização. Em Angicos, os alunos discutiam. Aprenderam a questionar, modificar, renovar e corrigir a realidade. Também produziam frases que expressam a formação de uma conscientização política em elaboração. Essas frases constam do jornal mimeografado e organizado pela equipe responsável pela experiência (GERMANO; PAIVA, 2006, p. 13):

Quero aprender a ler para: melhorar de vida; ter outra vida; pra servir a mim e a quem precisar; e votar em quem merecer; $\mathrm{O}$ trabalho é cultura; $\mathrm{O}$ trabalho é que dá honradez ao homem; O povo precisa de igualdade, justiça, trabalho, alimento; O povo quer melhorar de vida, deixar de ser massa.

Assim, esse povo começava a construir sua resistência e emancipação a anos de dominação, através da assimilação de práticas educativas e sociais. Em Angicos, os participantes (alunos) desse projeto eram pessoas de baixa renda ou sem renda alguma, agricultores, lavadeiras, donas de casa, pedreiros e até mesmo os presos receberam autorização para freqüentarem as aulas, o que faziam acompanhados de policiais. Ao final da 
experiência, os que conseguiram se "formar", escreveram ao Presidente João Goulart, pedindo indulto, que foi concedido.

É interessante observar as palavras de Melo (2011, p.02), ao lembrar a experiência de alfabetização vivenciada. Ela era criança, com apenas seis anos de idade e acompanhava os pais, estudando juntamente com eles, o que foi muito proveitoso para ela: "De acompanhar meus pais, acabei me alfabetizando antes deles".

Em outra entrevista, em que Melo (2007, p. 02) relatou suas lembranças dessa experiência educacional, observou que não guardara documento algum, tudo estava marcado na memória, pois seus pais queimaram tudo, inclusive seus cadernos que guardava embaixo do colchão da cama; teveram medo! Achavam que eram comunistas! Lembrou que aprendeu a ler sem que a professora percebesse. Era tão pequena que para escrever no quadro, precisava de um tamborete. Suas lembranças são involuntárias e vêm à tona, à medida que os temas são colocados, sem esforço de memória. Assim, fala da metodologia utilizada pelo projeto: a palavra geradora, que era conhecida por todos ("todos sabiam o que ela representava", ou "coisas da natureza ou da cultura"), era colocada no quadro. A depoente recorda como foi trabalhada a letra "i", das comparações feitas com a realidade. A professora dizia: "O jeito de parar o burro" . Depois era passado filme, slides, de acordo com o tema que estava sendo trabalhado. Se fosse a palavra "tijolo", passaria a construção. Relembra, ainda que na última aula, foi premiada pelo Presidente da República, Sr. João Goulart, que veio a Angicos para diplomar os formandos. Ele mandou que lesse o jornal, ele próprio apontando com sua caneta. Após a leitura, o Presidente falou que podia escolher um presente: "Eu escolhi uma bolsa para levar os livros para a escola". Sabe, no entanto que o Presidente deu um valor maior, pois seu pai comprou brinquedos, entre outras coisas.

Essas são reminiscências que não se tornaram públicas, mas que são conhecidas por um pequeno grupo. Passados quase 50 anos da experiência, essas memórias já sofreram várias transformações, foram desmontadas, organizadas, juntamente com as imagens que foram redesenhadas a partir de novas subjetividades que se configuraram em momentos e contextos determinados. Porém, o núcleo do rememorado permanece o mesmo.

No que se refere às contribuições da experiência de Angicos para a educação de jovens e adultos hoje, a Sra. Maria Eneide de Araújo Melo, que é professora do projeto Movimento de Alfabetização de Jovens e Adultos (MOVA), da Petrobrás, diz que respeitando as diferenças do momento atual, tudo é aplicado hoje. É feita a pesquisa de campo, "escolho o bairro ou mesmo a cidade e pelas falas, percebe-se o que querem. Daí tira-se as palavras geradoras, observando-se as potencialidades e as necessidades" (MELO, 2011, p. 05). A depoente ainda relata que quando pequena queria ser como Valquíria Félix, estudante de Direito, sua professora na época do projeto, mas na verdade, hoje, refletindo sobre isso, ela entende que queria mesmo era ser professora, e Valquíria era o modelo.

Seu pai, Sr. Severino Araújo, que no início dos anos 1960 tinha mais ou menos 30 anos, e ia para o Círculo de Cultura juntamente com a esposa, Francisca de Andrade de Araújo, e a filha, lamenta a repressão militar que impediu a continuidade do projeto:

Foi uma época muito boa. O pouco que aprendi, me serviu para a vida toda. Foi péssimo ter acabado. Poderia ter aprendido muito mais. Foi péssimo porque eu queria ter continuado a aprender. E depois fui obrigado a queimar todo o material (ARAÚJO, 2006, p. 01).

Essas lembranças deixaram o Sr. Francisco Araújo bastante triste. Percebe-se em suas palavras a crença na educação, resquícios das idéias que permeavam o início dos anos 60, do século XX. O ato de rememorar é constituído de memória e esquecimento. As realizações que poderiam ter ocorrido na vida do Sr. Francisco foram impedidas pelo violento término do 
projeto, embora sua filha, 5 (cinco) anos depois, afirme que a vida de todos modificou-se para melhor com a participação na experiência.

[...] o instante do rememorar implica o lembrar e o imaginar, pois apenas traços destas experiências podem ser resgatados; elas nunca serão representadas - trazidas para o presente de novo - tais como ocorreram no passado. Além disso, por mais que se possa resgatar do passado, há sempre lacunas de lembranças: a memória do esquecimento (LE VEN; FARIA; MOTTA, 1997, p. 215).

$\mathrm{O}$ ato de lembrar tem suas especificidades. A memória remete a um tempo próprio, peculiar, que não é nem cronológico nem linear. Mas apesar desse tempo ambíguo, descontínuo, é impossível separar os fatos de sua interpretação. Nas lembranças do ex-aluno ocorre uma fusão imperceptível entre Memória e História. Elas se cruzam, se enriquecem e não mais se separam, tornando-se um só tecido. A memória enriquece a perspectiva da História, assim como certos registros da História podem passar para a memória.

Uma outra aluna, Idália Marrocos da Silva, que na época do projeto tinha 34 anos, "dona-de-casa", relembra o debate realizado no Círculo de Cultura, o que lhe causava prazer: "Eu gostava das perguntas que a professora fazia. Uma vez ela me perguntou o que o rico fazia ao pobre. Eu respondi que o rico era uma muriçoca que pegava a pessoa dormindo e sugava seu sangue". Interessante observar a representação da ex-aluna. Angicos é uma cidade que sofre anualmente, sem trégua, o ataque de muriçocas. Ela também relembra que foi procurada, após o término das aulas por vários homens que não sabe quem eram. Mas afirma que, além de nunca ter tido medo de nada, nunca queimou coisa alguma (SILVA, 2011).

Pelos depoimentos, percebe-se que não existe um conflito entre memórias coletivas. Elas se completam. O elemento fragmentário da temporalidade, típico do registro pessoal ou coletivo é preservado. As lembranças surgem marcadas por fragmentos do passado e pela configuração do presente. Elas são apresentadas enquanto construção a partir do presente.

A lembrança', afirma Halbwachs, 'é em larga medida uma reconstrução do passado com ajuda de dados emprestados do presente e, além disso, preparada por outras reconstruções feitas em épocas anteriores e de onde a imagem de outrora se manifestou já bem alterada (SELIGMANN-SILVA, 2003, p. 70).

A experiência educacional vivenciada em Angicos faz parte da História e da memória. Ambas são chamadas para dar seu testemunho. Daí a importância de um trabalho conjunto entre História e Memória.

Às vezes nos limitamos a observar que nosso passado compreende dois tipos de elementos: os que podemos evocar quando desejamos e os que, ao contrário, não atendem ao nosso apelo, se bem que tão logo os procuramos no passado nossa vontade parece bater num obstáculo. Na verdade, dos primeiros podemos dizer que estão no terreno comum, no sentido de que o que nos é assim familiar ou facilmente acessível, é igualmente familiar ou acessível para os outros (HALBWACHS, 2006, p. 66).

Os encontros aconteciam à noite em vários Círculos de Cultura. Eram salas pequenas, iluminadas por um candeeiro a querozene, em que avós e netos muitas vezes conviviam no mesmo clima de descobertas e aprendizagem. As discussões se desenvolviam nos Círculos de Cultura, que eram espaços de alfabetização e de conscientização. Tome-se como exemplo o trabalho com a palavra geradora tijolo. Essa era estudada analiticamente com suas respectivas 
famílias ( ex.: ta - te - ti - to - tu; ja - je - ji - jo - ju; la - le - li - lo - lu.), que depois se transformavam em palavras, frases, parágrafos, textos. Todas as etapas eram alternadas e / ou acompanhadas pela discussão da realidade.

Esses espaços que funcionaram como Círculos de Cultura, em sua maioria, não existem mais, somente persistindo nas memórias dos participantes, que tentam situar os locais: "Era na Fazenda chamada de Chico Guilherme, era o filho de Chico Guilherme, mas era uma casa velha que tinha na fazenda; aí ele colocou lá umas pessoas..." (COSTA, 2011, p. 01). Outro situava-se onde atualmente é o parque de vaquejada, outro, ainda, estava caindo, e foi derrubado.

Ao final da experiência, 300 trabalhadores rurais foram alfabetizados, em 40 horas de aula e em apenas 45 dias. O sucesso dessa experiência valeu ao Professor Paulo Freire o convite para repensar a alfabetização de adultos em âmbito nacional. Porém, a Campanha Nacional de Alfabetização do governo João Goulart não chegou a ser posta em prática. $\mathrm{O}$ golpe militar puniu severamente essas experiências e muitos dos seus participantes.

Em Angicos, as pessoas tiveram muito medo. Queimaram toda a documentação. Houve um tempo em que não falavam sobre o assunto. Atualmente, a memória coletiva dessa experiência educacional luta para continuar existindo, em um processo de articulação entre presente e passado, interferindo na formação das representações presentes e misturando-se com as percepções imediatas. Acredita-se que em muito pouco tempo não existirão mais memórias individuais, mas apenas a memória coletiva, transformada em história.

\section{Considerações Finais}

A experiência educacional com jovens e adultos desenvolvida em Angicos, em 1963, sob a orientação do sistema Paulo Freire de Alfabetização, dispunha de potencialidades para transformar em muitos aspectos a realidade daquela pequena cidade, tendo em vista o conjunto de práticas sociais que estavam sendo exercitadas e assimiladas pela comunidade, que começava a assumir iniciativas que visavam seus próprios interesses.

Alguns depoentes testemunharam que suas vidas se modificaram com a experiência de alfabetização.

E as pessoas também que participaram mudaram de vida, melhoraram de vida; eu digo pela nossa. Papai trabalhava em agricultura e quando ele faltava eu aprendia e quando ele chegava eu ensinava, que era pra ele num ficar atrasado, mas ele depois mudou de vida, ele foi ser pedreiro, melhorou. Minha mãe entrou em aula de corte, foi costurar, quer dizer ela foi pra aula de corte porque ela já sabia ler; ela vendia lanche pras escolas, tudo isso ela desenvolveu depois que ela aprendeu, ela foi politizada, ela viu o que é ser cidadã, é participar. Eu acho que ela conseguiu. Meu pai depois de pedreiro foi comerciante, depois que teve comércio ele aprendeu a viajar sozinho, porque ele disse que lia nos ônibus. Ele fazia tudo sem saber de nada, ele já fazia; e depois [foi] que ele aprendeu. E sempre quiseram botar nós na escola porque tem pais que nem tem interesse, diz assim, eu num aprendi e to vivendo, mas os nossos pais não eles quiseram. Minha mãe fez uma carta naquele tempo (tem no livro de Carlos Lyra) ela pedindo bolsa de estudo pras filhas, e o que eu acho bonito é o começo que ela diz: eu agora não sou massa, sou povo. Bem conscientizada (MELO, 2011, p. 06).

As práticas desenvolvidas, apesar de efetivadas em um contexto diverso, podem servir como referência ao trabalho com jovens e adultos. Suas representações refletem "formas específicas de resistência simbólica", que transformam a experiência vivida. A depoente fala 
da importância da metodologia para o trabalho na EJA: "A metodologia, a grande contribuição é essa metodologia. Os projetos de Educação Popular aqui quase todos lidam com a metodologia de Paulo Freire, agora umas distorcidas [...]” (MELO, 2011, p. 07).

$\mathrm{O}$ trabalho com a memória trouxe para o presente lembranças do passado, refeitas e transformadas a partir das elaborações e interesses atuais, orientando para a articulação entre História e Memória, cruzamento enriquecedor para ambas. Também apontou para a necessidade e urgência em sua efetivação, para evitar que se percam informações importantes para preservação da memória coletiva, pois, vale salientar que alguns dos participantes mais velhos já não se encontram em condições de testemunhar, ou já tiveram seus óbitos registrados, outros, ainda, foram embora da cidade.

O processo de (re)significação das lembranças ocorre pela atividade reflexiva, pelo próprio dinamismo peculiar à memória, que a faz modificar, transformar, construir e reconstruir reminiscência para atribuir um sentido satisfatório a vida e para que exista correspondência entre identidades passadas e presentes.

Em Angicos, os participantes lembram e esquecem. Há lembranças que marcaram a experiência coletiva que fazem parte da história pública. Há também lembranças que pertencem a cada um, que tiveram significado em um grupo social mais restrito como a família, os amigos. Na maioria dos testemunhos, é a memória pessoal que se encontra em evidência.

\section{Referências}

ARAÚJO, Francisco. As 40 Horas de Angicos. Angicos, RN, 2006. Mimeografado.

BENJAMIN, Walter. Magia e técnica, arte e política: ensaios sobre literatura e história da cultura. Tradução Sérgio Paulo Rouanet. 7. ed. São Paulo: Brasiliense, 1994. (Obras Escolhidas, v. 1).

BERGSON, Henri. Matéria e memória: ensaio sobre a relação do corpo com o espírito. Tradução Paulo Neves da Silva. São Paulo: Martins Fontes, 1990.

BURKE, Peter. A Revolução Francesa da historiografia: a Escola dos Annales, 1929-1989. Tradução Nilo Odália. 3. ed. São Paulo: Editora da UNESP, 1991.

CARVAlho, M. E. G. Memórias da "Campanha de Pé no Chão": 1961-1964 (o testemunho dos participantes). 2000. 442 f. Tese (Doutorado em Educação) - Universidade Federal do Rio Grande do Norte, Natal, 2000.

COSTA, Valdice I. As 40 Horas de Angicos. Angicos, RN, 2011. Mimeografado.

GERMANO, José W.; PAIVA, M. Educação popular no Rio Grande do Norte: 1958-1960. Secretaria de Estado da Educação da Cultura e dos Desportos, Subcoordenadoria de Educação de Jovens e Adultos, Natal, n. 2, p. 3-16, 2006.

HALBWACHS, Maurice. A memória coletiva. São Paulo: Vértice, 2006.

HOBSBAWM, Eric. Era dos extremos. São Paulo: Companhia das Letras, 1995.

Tempos interessantes: uma vida no século XX. Tradução S. Duarte. São Paulo: Companhia das Letras, 2002.

JEDLOWSKI, Paolo. Memória e mídia: uma perspectiva sociológica. In: SÁ, C. P. (Org.). Imaginário e representações sociais. Rio de Janeiro: Museu da República, 2005. 
KARNAL, Leandro; TATSCH, Flávia Galli. Documento e história: a memória evanescente. In: PINSKY, Carla B; LUCA, Tânia Regina de. (Orgs.). O historiador e suas fontes. São Paulo: Contexto, 2009.

LE VEN, Michel M.; FARIA, Érica de; MOTTA, Miriam H. de Sá. História oral de vida: o instante da entrevista. In: VON SIMSON, Olga R. de Morais (Org.). Os desafios contemporâneos da história oral. Campinas: CMU Publicações, 1997.

LYRA, Carlos. As quarenta horas de Angicos: uma experiência pioneira de educação. São Paulo: Cortez, 1996.

MADRUGA, W. Paulo Freire: educação e desinformação. Tribuna do Norte, Natal, 21 ago. 2005.

MELO, Maria Eneide de Araújo. As 40 Horas de Angicos. Angicos, RN, 2007. Mimeografado.

As 40 Horas de Angicos. Angicos, RN, 2011. Mimeografado.

SELIGMANN-SILVA, M. Reflexões sobre a memória, a história e o esquecimento. In: (Org.). História, memória e literatura: o testemuno na era das catástrofes.

Campinas, SP: Editora Unicamp, 2003.

MONTENEGRO, Antônio Torres. História oral e memória: a cultura popular revisitada. São Paulo: Contexto, 1996.

SILVA, Dicla N; ALCÂNTARA, Vitória C; ELEUTÉRIO, Paula F. da S. A educação de jovens e adultos e sua trajetória na SECD. Secretaria de Estado da Educação da Cultura e dos Desportos, Subcoordenadoria de Educação de Jovens e Adultos, Natal, n. 10, p. 6-12, 2006.

SILVA, Idália M. As 40 Horas de Angicos. Angicos, RN, 2011. Mimeografado.

SOARES, Magda. Metamemórias-memórias: travessia de uma educadora. 2. ed. São Paulo: Cortez, 2001.

VASCONCELOS, H. A campanha de pé no chão. Natal, RN, 2000. Mimeografado.

\section{Notas:}

\footnotetext{
${ }^{1}$ Professora de História da Educação da Universidade Federal da Paraíba e pesquisadora do Grupo de Estudos e Pesquisas História da Educação da Paraíba - HISTEDBR/GT - PB.

${ }^{2}$ Graduanda em Pedagogia e voluntária de iniciação científica.

${ }^{3} \mathrm{O}$ atual trabalho tem como fonte o projeto de iniciação científica que estamos desenvolvendo na UFPB (20102011), nomeado Educação de Jovens e Adultos em 40 Horas: Angicos/RN - 1963 (História e Memórias).

4 Para ver a história escrita dessa experiência, vale consultar LYRA, Carlos. As quarenta horas de Angicos: uma experiência pioneira de educação. São Paulo: Cortez, 1996.

5 Nessa época, o burro era o meio de transporte mais utilizado pelas populações interioranas, sendo utilizada a expressão "aí", que com o tempo transformou-se em "i”, significando que aquele era o lugar de parada.
} 